\title{
CARREIRA TRADICIONAL OU MODERNA? UM ESTUDO COM ALUNOS DA REDE MUNICIPAL DE ENSINO DE SÃO JOSÉ DOS CAMPOS/SP
}

DOI: 1014211/regepe.v5i1.282

Artigo recebido em: 22/06/2015 Artigo aprovado em: 13/11/2015

Aline Campos Figueiredo - Instituto Federal de Minas Gerais ${ }^{1}$ Antônio Del Maestro Filho - Universidade Federal de Minas Gerais ${ }^{2}$

Lucas Maia dos Santos - Instituto Federal de Minas Gerais ${ }^{3}$

Resumo: Este artigo analisou a percepção de 185 alunos concluintes do Ensino Fundamental da rede municipal de ensino de São José dos Campos/SP sobre a relação entre educação empreendedora e a formação da visão de carreira. Na base teórica há os conceitos de tipos de carreira profissional, empreendedorismo e educação empreendedora. Optou-se pela realização de um estudo exploratório, descritivo e quantitativo por meio de análise fatorial exploratória e modelagem de equações estruturais. Houve a confirmação da validade nomológica-estrutural do modelo proposto e evidências de que na percepção dos alunos concluintes do ensino fundamental de São José dos Campos, a relação da educação empreendedora com a carreira moderna/proteana é mais intensa em comparação à carreira tradicional.

Palavras-chave: Educação; Empreendedorismo; Carreira Tradicional; Carreira Moderna.

\section{TRADITIONAL OR MODERN CAREER? A STUDY ABOUT STUDENTS OF MUNICIPAL EDUCATION IN SÃO JOSÉ DOS CAMPOS, SP, BRAZIL}

Abstract: This paper analyzed the perception of 185 graduating elementary school students of the municipal school system of São José dos Campos/SP on the relationship between entrepreneurial education and career vision formation. In the theoretical basis there are the concepts of types of careers, entrepreneurship and entrepreneurial education. This research is exploratory, descriptive and quantitative study through exploratory factor analysis and structural equation modeling. There was confirmation of the nomological-structural validity of the proposed model and evidences that the perception of graduating elementary school students of São José

\footnotetext{
${ }^{1}$ Endereço: Av. Serra da Piedade, 299, Bairro Conjunto Morada da Serra, Sabará-MG. CEP 34515640. E.mail: aline.figueiredo@ifmg.edu.br.

${ }^{2}$ E-mail: maestro@face.ufmg.br

${ }^{3}$ E-mail: lucas.maia@ifmg.edu.br
}

FIGUEIREDO, A. C.; DEL MAESTRO FILHO, A.; SANTOS, L. M. Carreira tradicional ou moderna? Um estudo com alunos da rede municipal de ensino de São José dos Campos/SP. Revista de Empreendedorismo e Gestão de Pequenas Empresas, v.5, n.1, 2016. 
dos Campos is that the relationship between Entrepreneurial Education and Modern/Protean Career is more intense than Traditional Career.

Keywords: Education; Entrepreneurship; Traditional Career; Modern Career.

\section{Introdução}

A educação possui um importante papel na formação dos profissionais e sua empregabilidade. Porém, poucos estudos brasileiros analisam o impacto da educação na formação profissional dos estudantes do Ensino Fundamental dos municípios.

Neste contexto, esta pesquisa pretende analisar a relação entre algumas das perspectivas de educação empreendedora e a formação da visão de carreira profissional dos alunos concluintes do Ensino Fundamental da rede municipal de ensino de São José dos Campos/SP.

A proposta de educação empreendedora que será abordada nesta pesquisa tem como foco direcionar os indivíduos para a autonomia na escolha e desenho da sua carreira profissional, desviando da visão predominante de carreira tradicional que se configura como estática, rígida e vertical (DOLABELA, 1999; ACKAH; HEATON, 2004; BALASSIANO; VENTURA; FONTES FILHO, 2004; FERNANCEZ; ENACHE, 2008; BENDASSOLLI, 2009; ANDRADE; KILIMNIK; PARDINI, 2011).

A educação dos indivíduos representa um papel que vai além do conteúdo e se direciona a um preparo emocional e profissional capaz de oferecer subsídios às pessoas para determinar e perseguir seus objetivos de vida. Foi pensando nessa perspectiva de vida para seus cidadãos, que o município de São José dos Campos, local escolhido para desenvolver a pesquisa, implementou o programa de educação empreendedora nas escolas da rede de ensino municipal.

Percebe-se que, no referido modelo de educação, há uma preocupação em oferecer aos alunos das escolas públicas municipais uma capacitação adequada ao desenvolvimento de carreiras profissionais modernas/proteanas. (ACKAH; HEATON, 2004; BALASSIANO; VENTURA; FONTES FILHO, 2004; FERNANCEZ; ENACHE, 2008; BENDASSOLLI, 2009; ANDRADE; KILIMNIK; PARDINI, 2011).

FIGUEIREDO, A. C.; DEL MAESTRO FILHO, A.; SANTOS, L. M. Carreira tradicional ou moderna? Um estudo com alunos da rede municipal de ensino de São José dos Campos/SP. Revista de Empreendedorismo e Gestão de Pequenas Empresas, v.5, n.1, 2016. 
A partir deste fenômeno, o presente trabalho procura responder a seguinte questão: com qual tipo de carreira (tradicional ou moderna/proteana) estudantes da educação municipal de São José dos Campos apresentam uma relação mais intensa?

Observa-se que, dentre os desafios dos indivíduos em criar condições favoráveis ao desenvolvimento de uma carreira moderna/proteana está a capacidade de planejar seu futuro segundo seus sonhos e determinação de realização pessoal. Com maior liberdade, as pessoas passam a ter mais responsabilidade sobre seus futuros e sobre os rumos de suas vidas.

O objetivo proposto pela educação empreendedora direciona-se para a formação de indivíduos que sejam capazes de visionar e construir uma carreira profissional moderna/proteana baseada no protagonismo de sua autorrealização pessoal e profissional (BENDASSOLLO, 2009; ANDRADE; KILIMNIK; PARDINI, 2011).

Como estudos que contemplem as duas variáveis educação e carreira são pouco explorados, esta pesquisa irá abrir espaço para futuros debates na área de administração e educação empreendedora que leve à construção de um modelo educacional mais voltado à transformação da sociedade, por meio de ações de indivíduos mais conscientes sobre sua responsabilidade para com sua vida, empregabilidade e capacidade de transformação social.

A seguir, apresenta-se a relação entre educação, empreendedorismo e carreira. Na seção referente aos métodos, serão explicadas as características da amostra e as técnicas multivariadas utilizadas, entre elas: a análise fatorial e a modelagem de equações estruturais.

Foi realizado o teste do modelo teórico e obteve-se evidências, exibidas nos resultados, de que o modelo de educação empreendedora, desenvolvido pelo município de São José dos Campos, possui uma relação mais intensa com o modelo de carreira moderna/proteana, porém, ainda mantendo relação menos intensa com o modelo tradicional de carreira. Isso dá indícios de que o modelo de educação implementado pelo município tem contribuído para o pensamento crítico de

FIGUEIREDO, A. C.; DEL MAESTRO FILHO, A.; SANTOS, L. M. Carreira tradicional ou moderna? Um estudo com alunos da rede municipal de ensino de São José dos Campos/SP. Revista de Empreendedorismo e Gestão de Pequenas Empresas, v.5, n.1, 2016. 
estudantes do Ensino Fundamental sobre o desenho de suas carreiras, mesmo que a percepção sobre a importância da carreira tradicional ainda esteja presente.

\section{Referencial Teórico}

Chanlat (1995) indica que a carreira é tida como uma sequência de experiências que envolvem a relação do indivíduo com o mundo do trabalho. Sob esse mesmo ponto de vista, a carreira pode ser entendida como uma sequência de atitudes e comportamentos, organizada num determinado espaço de tempo que irá variar de acordo com a percepção e aspirações profissionais de cada indivíduo.

Assim, o conceito de carreira está ligado à história do indivíduo e sua atitude perante seu desenvolvimento profissional. Outros autores também abordam 0 conceito de carreira (HALL, 1996; EVANS, 1996; FILION; LAFERTÉ, 2003; BALASSIANO; VENTURA; FONTES FILHO , 2004; LEMOS, 2010; BARUCH, 2011).

Conforme o modelo tradicional, as empresas são as principais responsáveis pela carreira de seus empregados. Neste enfoque, a carreira é mais estável e a principal medida de sucesso na carreira é a progressão vertical dentro da organização. Já o modelo moderno de carreira é marcado pela instabilidade, descontinuidade, horizontalidade. $\mathrm{Na}$ abordagem moderna, os indivíduos são os principais responsáveis por suas carreiras e o principal atributo de sucesso é o psicológico, inerente de cada indivíduo (BENDASSOLLI, 2009; ANDRADE; KILIMNIK; PARDINI , 2011).

Concomitante ao conceito transcrito por Chanlat (1995; 1996) e Hall (1996), apresenta-se o conceito de carreira proteana, cujo principal objetivo é a realização pessoal, emocional e profissional do indivíduo. Neste modelo de carreira, dirigida pelas pessoas, a noção do indivíduo sobre sucesso profissional está relacionada ao sucesso psicológico e ao objetivo de vida de cada um. Esse modelo contrapõe ao modelo tradicional de sucesso, que se concentrava na busca pela escalada dos níveis hierárquicos em uma organização, podendo também ser compreendido como sucesso por outros indivíduos.

FIGUEIREDO, A. C.; DEL MAESTRO FILHO, A.; SANTOS, L. M. Carreira tradicional ou moderna? Um estudo com alunos da rede municipal de ensino de São José dos Campos/SP. Revista de Empreendedorismo e Gestão de Pequenas Empresas, v.5, n.1, 2016. 
Para o autor, a abordagem de carreira proteana considera três espaços de expressão do indivíduo: o pessoal, o familiar e o profissional. Em cada um desses espaços, o indivíduo desenvolve subentidades que desempenham diferentes papéis na vida e na carreira profissional do indivíduo (BENDASSOLLI, 2009; ANDRADE; KILIMNIK; PARDINI, 2011).

Segundo Balassiano, Ventura e Fontes Filho (2004), o modelo de carreira proteana e moderna é uma tendência natural frente ao contexto que se vive hoje na sociedade contemporânea. Alterações tecnológicas e sociais têm causado modificações na relação entre empregados e organizações, criando novas formas de relações de trabalho. Encontra-se, então, nesse contexto, a responsabilidade da sociedade em desenvolver indivíduos cada vez mais capazes de se adaptarem a essa autonomia e responsabilidade sobre suas vidas e carreiras profissionais (ANDRADE; KILIMNIK; PARDINI, 2011).

Balassiano, Ventura e Fontes Filho (2004) destaca que as aberturas e os encaminhamentos profissionais no interior dos modelos tradicional e moderno são múltiplos e podem ser reagrupados e tipificados segundo a ordem colocada e demonstrada na Tabela 1.

O tipo de carreira burocrática se caracteriza pelo desenvolvimento dentro de uma carreira direcionada e consolidada na pirâmide hierárquica de uma organização. Um exemplo desse tipo de carreira é a de serviço público em que os profissionais transpõem os níveis de sua carreira de acordo com as políticas de mérito da organização pública. É um tipo de carreira ameaçado pela nova ordem do estado e dinâmica do mercado de trabalho contemporâneo (FERNANCEZ; ENACHE, 2008; BENDASSOLI, 2009; ANDRADE; KILIMNIK; PARDINI, 2011).

A carreira de tipo profissional, também mencionada por Balassiano, Ventura e Fontes Filho (2004), caracteriza-se pelo diferencial de certo saber, da especialização, da profissão e da reputação. Seu avanço se faz à medida que o profissional adquire experiência, conhecimento e se torna referência para crescer em torno da sua profissão, não necessariamente dentro de uma única organização.

FIGUEIREDO, A. C.; DEL MAESTRO FILHO, A.; SANTOS, L. M. Carreira tradicional ou moderna? Um estudo com alunos da rede municipal de ensino de São José dos Campos/SP. Revista de Empreendedorismo e Gestão de Pequenas Empresas, v.5, n.1, 2016. 


\section{REG \\ Revista de Empreendedorismo \\ www.regepe.org.br}

e Gestão de Pequenas Empresas

\begin{tabular}{l|l|l|l|l|l} 
TABELA 1 - TIPOS DE CARREIRA & \multicolumn{1}{c}{$\begin{array}{l}\text { Elemento } \\
\text { Tipos de } \\
\text { Carreira }\end{array}$} & $\begin{array}{l}\text { Recursos } \\
\text { principais } \\
\text { central de } \\
\text { ascensão }\end{array}$ & $\begin{array}{l}\text { Tipo de } \\
\text { organização }\end{array}$ & $\begin{array}{l}\text { Tipo de } \\
\text { sociedade. }\end{array}$ \\
\hline Burocrática & $\begin{array}{l}\text { Posição } \\
\text { hierárquica }\end{array}$ & $\begin{array}{l}\text { Avanço de uma } \\
\text { posição } \\
\text { hierárquica à } \\
\text { outra }\end{array}$ & $\begin{array}{l}\text { Organizaçães } \\
\text { de grande } \\
\text { porte }\end{array}$ & $\begin{array}{l}\text { Os números } \\
\text { de escalões } \\
\text { existentes }\end{array}$ & $\begin{array}{l}\text { Sociedade } \\
\text { de } \\
\text { empregados }\end{array}$ \\
\hline Profissional & $\begin{array}{l}\text { Saber e } \\
\text { reputação }\end{array}$ & $\begin{array}{l}\text { Profíssão, } \\
\text { perícia } \\
\text { Habilidades } \\
\text { profissionais }\end{array}$ & $\begin{array}{l}\text { Organização } \\
\text { de peritos } \\
\text { Burocracia } \\
\text { Profissional }\end{array}$ & $\begin{array}{l}\text { O nível de } \\
\text { perícia e de } \\
\text { reparação }\end{array}$ & $\begin{array}{l}\text { Sociedade } \\
\text { de peritos }\end{array}$ \\
\hline Empreendedora & $\begin{array}{l}\text { Capacidade } \\
\text { de criação } \\
\text { inovação }\end{array}$ & $\begin{array}{l}\text { Criação de } \\
\text { novos valores, } \\
\text { de novos } \\
\text { produtos e } \\
\text { serviços }\end{array}$ & $\begin{array}{l}\text { Micro, } \\
\text { pequenas e } \\
\text { médias } \\
\text { empresas }\end{array}$ & $\begin{array}{l}\text { Capacidade } \\
\text { pessoal } \\
\text { As } \\
\text { exigências } \\
\text { externas }\end{array}$ & $\begin{array}{l}\text { Sociedade } \\
\text { que valoriza } \\
\text { a iniciativa } \\
\text { individual }\end{array}$ \\
\hline Sociopolítica & $\begin{array}{l}\text { Habilidade } \\
\text { sociais } \\
\text { Capital de } \\
\text { relações }\end{array}$ & $\begin{array}{l}\text { Conhecimento } \\
\text { Relações } \\
\text { Parentesco } \\
\text { (Rede social) }\end{array}$ & $\begin{array}{l}\text { Familiar } \\
\text { Comunitária } \\
\text { de Clãs }\end{array}$ & $\begin{array}{l}\text { Os números } \\
\text { de relações } \\
\text { conhecidas } \\
\text { e ativas }\end{array}$ & $\begin{array}{l}\text { Sociedade } \\
\text { de clãs }\end{array}$ \\
\hline
\end{tabular}

FONTE: Adaptado de Balassiano, Ventura e Fontes Filho (2004).

Outro tipo mencionado pelo autor, é a carreira empreendedora, com caráter mais individualista e, apesar de mais arriscada, tende a oferecer maiores ganhos ao profissional que escolheu desenvolvê-la. Trata-se de uma carreira baseada na inovação e seu sucesso está na capacidade de visão e realização de oportunidades enxergadas pelo indivíduo que a desenvolve.

Para Dolabela (2003), o ato de empreender vai além da inovação, ele está ligado à capacidade de modificar a realidade para dela obter a autorrealização e oferecer valores positivos para a coletividade. Com isso, empreender é um ato essencialmente humano dominado por emoção, desejos, sonhos, valores, ousadia de enfrentar as incertezas, rebeldia e crença na capacidade de mudar o mundo e indignação perante as injustiças sociais.

Por fim, o autor aborda sobre a carreira do tipo sociopolítico que se baseia nas habilidades sociais e de relacionamento desenvolvidas pelos indivíduos. Esse tipo de carreira é muito comum nas empresas familiares e comunitárias. Neste caso, a carreira é desenvolvida a partir dos relacionamentos e não tanto pela criatividade, competência e talentos.

Os conceitos de carreira evoluem à medida que as mudanças sociais emergem no contexto das políticas e história das diferentes sociedades. Percebe-se

FIGUEIREDO, A. C.; DEL MAESTRO FILHO, A.; SANTOS, L. M. Carreira tradicional ou moderna? Um estudo com alunos da rede municipal de ensino de São José dos

Campos/SP. Revista de Empreendedorismo e Gestão de Pequenas Empresas, v.5, n.1, 2016. 
que a difusão de determinado conceito de carreira está diretamente relacionada à cultura e aos conceitos que os indivíduos desenvolvem sobre suas vidas. Entendese, assim, que a história de vida e a formação desses indivíduos serão o ponto central de identificação e disposição para o desenvolvimento de uma carreira profissional tradicional ou moderna.

Pelo viés utilizado na educação fundamental dos municípios de São José dos Campos, as tipologias apresentadas na Tabela 1 dão à carreira burocrática um aspecto mais aproximado das características de carreira tradicional e as outras possuem características mais associadas à carreira moderna.

A visão sobre carreira moderna é principalmente defendida por Andrade, Kilimnik e Pardini (2011) e Baruch (2011), que a conceitua a partir das mudanças sociais ocorridas na sociedade, em que se destacam: a feminização do mercado de trabalho; elevação dos graus de instrução; cosmopolitação do tecido social; afirmação dos direitos dos indivíduos; globalização da economia; flexibilização do trabalho; entre outras mudanças da sociedade e organizações.

Verifica-se assim, que as carreiras modernas, como as proteanas, exigem dos trabalhadores maior versatilidade e capacidade de se "autoempresariar", o que leva a assumir riscos na trajetória e direcionamento de carreira.

Segundo Paiva (1998, p. 17), "a qualificação real, o saber fazer, o saber comportar-se de acordo com as situações diversas, o saber mostrar adequadamente a capacidade de acionar conhecimentos e virtudes, tornou-se mais importante que a qualificação formal". Esse posicionamento leva à reflexão de que o trabalhador contemporâneo tende a ter cada vez menor garantia pelo emprego por tempo prolongado, mas por sua empregabilidade, o que se entende pela capacidade do profissional em agregar valor ao seu trabalho através de competências desenvolvidas que estejam sintonizadas com as novas necessidades do mercado de trabalho (MINARELLI, 2010).

Baruch (2011) aponta que o contexto em que se desenvolvem as carreiras na contemporaneidade vem sofrendo transformações de acordo com as aspirações dos indivíduos e empresas. Porém, a autora também ressalta que as empresas nem

FIGUEIREDO, A. C.; DEL MAESTRO FILHO, A.; SANTOS, L. M. Carreira tradicional ou moderna? Um estudo com alunos da rede municipal de ensino de São José dos Campos/SP. Revista de Empreendedorismo e Gestão de Pequenas Empresas, v.5, n.1, 2016. 
sempre estão em consonância com esse contexto e acabam não oferecendo um ambiente adequado ao estímulo para desenvolvimento de uma carreira proteana.

\section{Educação Empreendedora}

Ao considerar o empreendedorismo como "forma de ser", Dolabela (2003, p. 37) propõe, pelo conceito de Pedagogia Empreendedora, a desvinculação do conceito de empreendedor de uma atividade específica. $O$ autor considera o empreendedorismo como "algo ligado a estilo de vida, visão de mundo, protagonismo, inovação, capacidade de produzir mudanças em si mesmo e no meio ambiente, meios de buscar autorrealização, incluindo padrões de reação diante das ambiguidades e incertezas".

Dessa forma, ele argumenta que a Pedagogia Empreendedora é um ambiente para a construção conjunta do conhecimento, e não para transferência linear; um ambiente de preparação para a vida, e não de formação para o emprego, uma ocupação funcional. Dentro da proposta desenvolvida pelo autor, a educação empreendedora tem como principal objetivo formar cidadãos capazes de protagonizarem seus próprios destinos e de agirem a fim de modificar sua relação com o outro, com a natureza, com a sociedade e de se recriarem constantemente.

Filion e Laferté (2003, p. 9) destacam que "falar de empreendedorismo e de educação significa canalizar o conhecimento para uma melhor realização do potencial de cada um". Esses autores defendem que a educação empreendedora necessita de uma engenharia pedagógica específica, pois o empreendedorismo se aprende principalmente pela transmissão de valores, por osmose e por trocas de experiências com aqueles que o praticam. Os autores analisam o descompasso do sistema tradicional de ensino para formação de indivíduos aptos a uma trajetória de carreira mais independente e multidirecionada de acordo com os objetivos e sonhos de cada um (DOLABELA, 2003; LOPES; TEIXEIRA, 2010).

No Brasil, já é reconhecida pela Lei de Diretrizes e Bases, LDB 9394 de 20 de dezembro de 1996 (BRASIL, 2005) a importância de se desenvolver, já no ensino

FIGUEIREDO, A. C.; DEL MAESTRO FILHO, A.; SANTOS, L. M. Carreira tradicional ou moderna? Um estudo com alunos da rede municipal de ensino de São José dos Campos/SP. Revista de Empreendedorismo e Gestão de Pequenas Empresas, v.5, n.1, 2016. 
básico, conhecimentos orientados ao trabalho. Este apontamento da LDB demonstra a preocupação de formar e direcionar os cidadãos brasileiros para a construção de suas carreiras profissionais a partir do ensino básico.

Isso vem de encontro com a proposta da educação empreendedora, que tem como objetivo, desenvolver pessoas ativas e capazes de protagonizar suas vidas, garantindo uma sociedade mais independente, desenvolvida e democrática.

Portanto, conforme a proposta apresentada pela educação empreendedora, é possível reconhecer o seu alinhamento entre formação básica e o mundo do trabalho. Formação essa que seja capaz de desenvolver indivíduos cujos perfis sejam mais adequados para o desenvolvimento de uma trajetória de carreira voltada ao modelo moderno/proteano.

Diante dessa análise, identifica-se a necessidade de realizar estudos que confirmem a relação da educação empreendedora com a formação de profissionais capazes de empreender a partir da visualização e realização de um futuro conforme seus sonhos, e que os direcionem à construção de uma sociedade mais rica e justa para todos.

\section{São José dos Campos e sua história com a educação empreendedora}

A cidade de São José dos Campos, um município do Estado de São Paulo, com uma população aproximada de 630 mil habitantes (IBGE, 2015), desde 1999 desenvolve um programa de educação empreendedora nas escolas públicas municipais. O principal objetivo para a implantação do programa foi desenvolver uma educação de qualidade capaz de formar cidadãos críticos e empreendedores. Este programa foi introduzido no currículo das escolas municipais através da Resolução CME n. 03/02 do município. A partir daí, projetos e programas de estímulo ao potencial e criatividade dos alunos foram desenvolvidos nas escolas municipais, o que vem estimulando a motivação desses alunos e a geração de oportunidades a partir de uma interação cada vez maior entre escola e a comunidade local (LOPES; TEIXEIRA, 2010).

FIGUEIREDO, A. C.; DEL MAESTRO FILHO, A.; SANTOS, L. M. Carreira tradicional ou moderna? Um estudo com alunos da rede municipal de ensino de São José dos Campos/SP. Revista de Empreendedorismo e Gestão de Pequenas Empresas, v.5, n.1, 2016. 
O município de São José dos Campos - SP tornou-se referência na aplicação da educação empreendedora a partir do ensino básico. Nas escolas municipais da cidade, os alunos começam a receber as primeiras lições de empreendedorismo com 4 anos de idade. Através do envolvimento de professores e diretores das escolas municipais, alguns projetos de complementação curricular (Educação do Consumidor, Profissional do Futuro, Aprendiz de Turismo e Miniempresa) foram adotados com o intuito de se promover a educação empreendedora no município.

A partir dos resultados bem-sucedidos dessas práticas, nasceu o "Programa de Empreendedorismo na Educação", com embasamento legal na Lei de Diretrizes e Bases da Educação Nacional - LDB no 9394, de 20 de dezembro de 1996, em seus Artigos 26 e 27; resolução CNE/CEB no 07/04/98; parecer CNE/CEB 4/98.

Em 2002, por intermédio da Secretaria Municipal de Educação e com a deliberação do Conselho Municipal de Educação de São José dos Campos (Parecer $\mathrm{CME}, \mathrm{n}^{\circ}$ 03/02), o "Programa de Empreendedorismo na Educação" tornou-se política pública de ensino e foi incluído na grade curricular das Escolas Municipais. Isso veio garantir a continuidade do programa, mesmo com a troca da gestão municipal.

O programa encontra-se organizado pela execução das seguintes ações: componentes curriculares (profissional do futuro e aprendiz de turismo), pedagogia empreendedora dos sonhos, jovem empreendedor primeiros passos, Júnior Achievement, Feira do Jovem Empreendedor, Centro de Educação EmpreendedoraCEDEMP e Laboratório do Jovem Empreendedor - LAJOE. Todas essas ações são mantidas sob a coordenação da Secretaria Municipal de Educação que promove a capacitação contínua de professores e profissionais envolvidos com os projetos.

Ainda dentro do programa, alguns projetos especiais são desenvolvidos com intuito de atingir um maior número de alunos, dentro das diversas faixas etárias. Destaca-se, assim, o projeto da "Pedagogia Empreendedora dos Sonhos", que tem como objetivo, "estimular e preparar o aluno para sonhar e buscar a realização do seu sonho, despertando o espírito empreendedor e incentivando a desenvolvê-lo" (DOLABELA, 2003, p. 32).

FIGUEIREDO, A. C.; DEL MAESTRO FILHO, A.; SANTOS, L. M. Carreira tradicional ou moderna? Um estudo com alunos da rede municipal de ensino de São José dos Campos/SP. Revista de Empreendedorismo e Gestão de Pequenas Empresas, v.5, n.1, 2016. 
Porém, o "Programa de Empreendedorismo na Educação" não para por aí, pois ainda conta com outros projetos em parcerias com o SEBRAE e a Júnior Achievement, que são: Jovem Empreendedores Primeiros Passos e Miniempresa.

No primeiro, o objetivo principal é "desenvolver o comportamento empreendedor por meio da vivência de um empreendimento, criando oportunidades para que os alunos possam tomar iniciativas e, com responsabilidade, envolver-se no enfrentamento de problemas reais do mundo dos negócios". Não muito diferente, o projeto de Miniempresa, organizado em parceria com a Júnior Achievement, General Motors do Brasil e Embraer, tem como objetivo "despertar no jovem a competência empreendedora, estimular o desenvolvimento pessoal e as habilidades básicas para a comunicação; fortalecer os princípios éticos e proporcionar vivência empresarial".

Esses projetos têm como público alvo, os alunos de $3^{\circ}$ ao $9^{\circ}$ ano e já capacitou mais de 500 professores para atuarem nas aulas e práticas vivenciadas nas escolas municipais.

Outra ação importante implementada pela prefeitura municipal é a Feira do Jovem Empreendedor Joseense. Essa ação é realizada a cada dois anos e trata-se de uma mostra dos programas e projetos de empreendedorismo existentes na Rede de Ensino Municipal. Nesta feira, os melhores trabalhos de Plano de Negócios desenvolvidos na disciplina "Profissional do Futuro" das escolas municipais são expostos e concorrem a prêmios.

Outra ação implementada com objetivo de dar suporte às práticas da educação empreendedora no município foi a criação do Laboratório do Jovem Empreendedor-LAJOE. O laboratório nasceu da preocupação com relação aos rumos que os alunos dariam aos seus projetos de empreendedorismo apresentados na feira. O intuito principal consiste em "aprimorar os projetos apresentados na Feira do Jovem Empreendedor Joseense através de ações que proporcionem conhecimentos técnicos e em gestão de negócios, agregando melhorias e tornandoos competitivos no mercado". Nesse caso, os projetos são encaminhados para análise e capacitação gerenciais e jurídicas por meio de Oficinas de Simulação de empresa para possível encaminhamento a incubadoras existentes.

FIGUEIREDO, A. C.; DEL MAESTRO FILHO, A.; SANTOS, L. M. Carreira tradicional ou moderna? Um estudo com alunos da rede municipal de ensino de São José dos Campos/SP. Revista de Empreendedorismo e Gestão de Pequenas Empresas, v.5, n.1, 2016. 
Por fim, com a finalidade de "disseminar a cultura empreendedora no município, viabilizando o desenvolvimento de ações com os alunos das escolas municipais e estaduais, propiciando o acesso de todos os interessados a um Centro de Educação", foi criado o Centro de Educação Empreendedora - CEDEMP. Nesse centro, são desenvolvidas atividades que visam complementar e sistematizar o trabalho realizado nas escolas, com o foco principal na difusão da cultura empreendedora no município de São José dos Campos. Além disso, a equipe de Educação Profissional Básica, vinculada ao CEDEMP, ministra cursos à comunidade que, além dos conteúdos específicos trabalhados, transmitem valores e conceitos de Empreendedorismo voltados para o desenvolvimento humano, social e econômico sustentável.

Portanto, ao analisar o modelo de educação empreendedora desenvolvido em São José dos Campos, é possível visualizar esse trabalho sob a perspectiva de desenvolver cidadãos mais voltados a uma carreira do tipo moderna/proteana. Partindo dessa perspectiva, nasce a proposta da referida pesquisa para este trabalho.

A seguir, serão apresentados os procedimentos metodológicos adotados para a realização desta pesquisa.

\section{Procedimentos Metodológicos}

Com base no pressuposto teórico apresentado, buscou-se analisar a relação entre educação empreendedora e a formação da visão de carreira profissional dos alunos concluintes do Ensino Fundamental da rede municipal de ensino de São José dos Campos/SP. O modelo proposto nesta pesquisa relaciona a educação empreendedora com a tendência de visão de carreira profissional tradicional ou moderna/proteana (BALASSIANO; VENTURA; FONTES FILHO, 2004; FERNANCEZ; ENACHE, 2008; BENDASSOLLI, 2009; ANDRADE; KILIMNIK; PARDINI , 2011).

FIGUEIREDO, A. C.; DEL MAESTRO FILHO, A.; SANTOS, L. M. Carreira tradicional ou moderna? Um estudo com alunos da rede municipal de ensino de São José dos Campos/SP. Revista de Empreendedorismo e Gestão de Pequenas Empresas, v.5, n.1, 2016. 
Esta pesquisa se classifica como exploratória e descritiva quanto aos fins e bibliográfica, documental e de campo quanto aos meios (GIL, 2010; VERGARA 2010).

$\mathrm{Na}$ análise documental, foram analisados documentos internos do Centro de Educação Empreendedora de São José dos Campos para descrever as atividades e projetos desenvolvidos na área de educação empreendedora. A pesquisa de campo foi realizada por meio de uma survey com alunos concluintes do Ensino Fundamental da rede de ensino municipal (GIL, 2010).

A pesquisa foi realizada em uma amostra não probabilística por conveniência (MAROCO, 2007), com alunos do 9ำ ano do Ensino Fundamental do sistema municipal de ensino de São José dos Campos - SP. A escolha deste método se justifica por considerar que nem todos os selecionados teriam a disponibilidade em responder à pesquisa, o que dificultaria a constituição de uma amostra probabilística.

A escolha do público e objeto de pesquisa deu-se porque São José dos Campos se destaca no território brasileiro por suas práticas de educação empreendedora aplicadas em escolas a partir do Ensino Infantil e pelo fato de os alunos do $9^{\circ}$ ano do Ensino Fundamental serem concluintes do ciclo completo da educação empreendedora desenvolvida no município (LOPES; TEIXEIRA, 2010).

Tendo como parâmetro de estimação os dados fornecidos pela Secretaria Municipal de Ensino de São José dos Campos, o número total de alunos regularmente matriculados em 2012 no 9ํaㅅ ano do Ensino Fundamental, era de 4.377. Então, para definição do tamanho da amostra, foi estabelecido um erro amostral padrão de 5\%, para um nível de segurança de $95 \%(Z=1,96)$, sendo considerada uma variabilidade amostral de 12,5\%. O valor da amostra foi obtido por intermédio da fórmula de Barnett (1991) e teve como resultado mínimo para os padrões estatísticos acima definidos, um total de 184 respondentes para aplicação do instrumento de pesquisa.

A amostra adequada, segundo Barnett (1991), seria de cento e oitenta e quatro respondentes e foram obtidos 186 casos válidos, dos 187 recebidos. É importante ressaltar que foram selecionadas duas escolas de cada uma das 5

FIGUEIREDO, A. C.; DEL MAESTRO FILHO, A.; SANTOS, L. M. Carreira tradicional ou moderna? Um estudo com alunos da rede municipal de ensino de São José dos

Campos/SP. Revista de Empreendedorismo e Gestão de Pequenas Empresas, v.5, n.1, 2016. 
(cinco) regiões (norte, sul, centro, oeste e leste) do município para reduzir problemas com a representatividade dos estudantes do município.

O instrumento utilizado para coleta de dados foi um questionário préelaborado, composto por questões em escala intervalar, variando de 1 (um) a 6 (seis) pontos, sendo 1 para "discordo totalmente" até 6 para "concordo totalmente". As questões foram elaboradas levando-se em consideração as características dos diferentes tipos de carreira e da educação empreendedora desenvolvida no universo pesquisado.

A primeira parte do questionário foi composta por 23 questões sobre a visão de carreira profissional, de acordo com os autores seminais (CHANLAT, 1995; 1996; HALL, 1996). A segunda parte foi constituída por 12 questões que investigaram a visão de futuro dos estudantes. Já a terceira parte foi composta por 6 questões referentes às características dos entrevistados (dados demográficos).

O questionário foi validado por juízes e por avaliação semântica. Além do mais, foram aplicados 10 (dez) questionários pré-teste com objetivo de averiguar a clareza das perguntas (EASTERBY-SMITH; THORPE; LOWE, 1991; GIL, 2010; VERGARA, 2010).

A aplicação da pesquisa foi autorizada através do processo 36178/2012, pela Secretaria Municipal de Educação, em 28 junho de 2012. A aplicação do questionário foi realizada no período de 30 julho de 2012 a 03 agosto do mesmo ano, por meio de visitas às escolas de cada região indicadas pela prefeitura municipal de São José dos Campos. Foi solicitado, além do questionário preenchido, o termo de Consentimento Livre e Esclarecido assinado pelo estudante e pelo seu representante legal. Foram distribuídos em torno de 700 questionários, com uma taxa de resposta de 27\%, correspondendo aos 187 questionários preenchidos.

$\mathrm{Na}$ análise dos dados, realizou-se uma análise exploratória, permitindo caracterizar a amostra, e uma análise descritiva dos dados, verificando a existência de dados ausentes no banco de dados (missing values), outliers (uni e multivariados), a normalidade dos dados e linearidade. Importante dizer que foram adotados os critérios de imputação dos valores ausentes com a substituição pela média, conforme recomendação de Hair et al. (2009).

FIGUEIREDO, A. C.; DEL MAESTRO FILHO, A.; SANTOS, L. M. Carreira tradicional ou moderna? Um estudo com alunos da rede municipal de ensino de São José dos Campos/SP. Revista de Empreendedorismo e Gestão de Pequenas Empresas, v.5, n.1, 2016. 
Após serem realizadas as análises exploratórias, definiu-se um modelo teórico-hipotético com a relação entre educação empreendedora e a percepção dos estudantes sobre os tipos de carreira. Isto foi feito por meio da Modelagem de Equações Estruturais (MEE) (FORNELL; BOOKSTEIN, 1982; MACKENZIE, 2001; HAENLEIN; KAPLAN, 2004; HENSELER; RINGLE; SINKOVICS, 2009).

Findada a descrição da metodologia utilizada na construção e análise da referida pesquisa, passa-se à apresentação dos resultados alcançados, para posteriores considerações e conclusões geradas pelo presente estudo.

\section{Resultados}

Quanto aos dados ausentes na coleta de dados, o teste Little's MCar apresentou estatística chi-quadrado não significativa a $1 \%$, revelando que os dados ausentes são aleatórios ao acaso (HAIR et al., 2009). Como os dados ausentes representaram menos de $10 \%$ das variáveis, foram substituídos pela média.

A análise de outlier univariados foi realizada pela análise das discrepâncias superiores a 1 (um) desvio padrão acima ou abaixo da média padronizada dos dados e pela medida $\mathrm{D}^{2}$ de Mahalanobis para os outlier multivariados. Este processo possibilitou a exclusão de apenas uma observação, fazendo com que a amostra final de análise fosse composta por 185 observações.

Quanto à normalidade dos dados, houve rejeição à 5\% de significância do teste de Kolmogorov-Smirnov, mostrando ausência de normalidade univariada e, consequentemente, multivariada (TABACHNICK; FIDEL, 2001; HAIR et al., 2009).

A Tabela 2 a seguir apresenta algumas características sobre a amostra de estudantes.

FIGUEIREDO, A. C.; DEL MAESTRO FILHO, A.; SANTOS, L. M. Carreira tradicional ou moderna? Um estudo com alunos da rede municipal de ensino de São José dos Campos/SP. Revista de Empreendedorismo e Gestão de Pequenas Empresas, v.5, n.1, 2016. 


\begin{tabular}{|c|c|c|c|c|}
\hline Região & $\begin{array}{l}\text { Norte }-36 \% \\
\text { Leste }-20 \% \\
\text { Sul }-12 \%\end{array}$ & $\begin{array}{l}\text { Centro - 19\% } \\
\text { Oeste - 12\% }\end{array}$ & Faixa etária & $\begin{array}{l}\text { Até } 14 \text { anos }-11 \% \\
\text { Possui } 14 \text { anos }-81 \% \\
\text { De } 15 \text { a } 16 \text { anos }-7 \% \\
\text { Não respondeu }-1 \%\end{array}$ \\
\hline Escolas & \multicolumn{2}{|c|}{$\begin{array}{l}\text { Mariana Teixeira Cornélio - } 27 \% \\
\text { Profa Otacília M. de Moura - } 12 \% \\
\text { Prof. Antônio Palma Sobrinho - } 12 \% \\
\text { Vera Babo de Oliveira - 10\% } \\
\text { Prof }{ }^{a} \text { Sônia Maria Pereira da Silva - 9\% }\end{array}$} & \multicolumn{2}{|c|}{$\begin{array}{l}\text { Prof }{ }^{a} \text { Aurea Cantinho Rodrigues - 7\% } \\
\text { Prof. Jacyra Vieira Baracho - 7\% } \\
\text { Prof }=\text { Lúcia Pereira Rodrigues - } 6 \% \\
\text { Prof }=\text { Sebastiana Cobra - } 6 \% \\
\text { Profãa Norma de Conti Simão - 5\% }\end{array}$} \\
\hline Renda & $\begin{array}{l}\text { Até } R \$ 650- \\
\text { De } R \$ 651 \text { a } \\
\text { De } R \$ 1301 \text { a } \\
\text { Acima de } R \$ \\
\text { Não responde }\end{array}$ & $\begin{array}{l}00,00-36 \% \\
000-32 \% \\
-18 \% \\
\%\end{array}$ & Gênero & $\begin{array}{l}\text { Masculino }-34 \% \\
\text { Feminino - } 65 \% \\
\text { Não respondeu - 1\% }\end{array}$ \\
\hline
\end{tabular}

FONTE: Os autores (2016).

A maioria dos entrevistados se concentra na região norte (36\%), seguida da região leste (20\%) e da região centro (19\%). A região sul e a oeste correspondem a $12 \%$ cada.

Observa-se que a Escola Municipal de Ensino Fundamental (EMEF) "Mariana Teixeira Cornélio" foi a que apresentou o maior número de respondentes, totalizando $27 \%$ das citações. Em segundo lugar, aparecem as EMEF "Prof. Otacílio M. de Moura" e "Prof. Antônio Palma Sobrinho", com 12\% das citações cada. Já em terceiro lugar, figura a EMEF "Vera Babo de Oliveira", com 10\%. As outras EMEF não receberam mais que $10 \%$ de citações.

A Tabela 2 também apresenta o gênero dos entrevistados. Pode-se verificar que $65 \%$ são do gênero feminino e $34 \%$ do masculino. Os outros $1 \%$ não responderam esta questão. Quanto a faixa etária, a maior parte possui 14 anos (81\%). Outros $11 \%$ possuem menos de 14 anos e outros $7 \%$ de 15 a 16 anos. Além disso, $1 \%$ não respondeu esta questão.

Com relação a renda familiar, $5 \%$ possui uma renda de "até $R \$ 650,00 "$. As categorias de maior frequência foram rendas "de $R \$ 651,00$ a $R \$ 1.300,00 "$ com $36 \%$ e "de $R \$ 1.301,00$ a $R \$ 2.600,00 "$ com $32 \%$. Outros $18 \%$ possuem uma renda superior a $\mathrm{R} \$ 2.600,00$ e 9\% não responderam a esta questão.

Com relação as percepções dos estudantes sobre educação e carreira, a Tabela 3 ilustra as estatísticas descritivas das respostas obtidas.

FIGUEIREDO, A. C.; DEL MAESTRO FILHO, A.; SANTOS, L. M. Carreira tradicional ou moderna? Um estudo com alunos da rede municipal de ensino de São José dos Campos/SP. Revista de Empreendedorismo e Gestão de Pequenas Empresas, v.5, n.1, 2016. 


\section{TABELA 3 - ESTATÍSTICA DAS PERCEPÇÕES DOS ESTUDANTES SOBRE EDUCAÇÃO} EMPREENDEDORA E TIPO DE CARREIRA DOS ESTUDANTES

\begin{tabular}{|c|c|c|c|}
\hline Variáveis & Média* & $50 \%$ & Desvio \\
\hline V1. Eu já tenho certeza da carreira profissional que irei seguir no futuro. & 4,01 & 4,00 & 1,65 \\
\hline V2. Acredito que a responsabilidade sobre a minha carreira profissional será totalmente minha. & 5,21 & 6,00 & 1,21 \\
\hline V3. Espero conseguir um bom emprego para ter estabilidade e uma vida segura. & 5,81 & 6,00 & 0,61 \\
\hline V4. Acredito que a responsabilidade sobre a minha carreira profissional depende da empresa em que trabalharei. & 2,54 & 2,00 & 1,64 \\
\hline V5. Ainda não pensei na minha carreira profissional, pois acredito que há muito tempo para pensar nisso. & 2,18 & 1,00 & 1,61 \\
\hline V6. Nunca tive estímulo na escola para pensar no meu futuro profissional. & 1,87 & 1,00 & 1,53 \\
\hline $\begin{array}{l}\text { V7. Acredito que serei realizado na vida se puder ter o emprego dos sonhos e tempo para me dedicar à família e à } \\
\text { vida pessoal. }\end{array}$ & 5,43 & 6,00 & 1,05 \\
\hline $\begin{array}{l}\text { V8. Estou disposto a trabalhar muito, pois pretendo ganhar muito dinheiro, não importa o quanto terei que sacrificar } \\
\text { minha família e minha vida pessoal. }\end{array}$ & 2,21 & 2,00 & 1,55 \\
\hline V9. Visualizo que um bom trabalho é aquele que me oferece grandes ganhos materiais. & 2,95 & 3,00 & 1,71 \\
\hline $\begin{array}{l}\text { V10. Visualizo que um bom trabalho é aquele em que posso me realizar pessoalmente e profissionalmente, e ainda } \\
\text { obter ganhos materiais. }\end{array}$ & 5,24 & 6,00 & 1,27 \\
\hline V11. Pretendo como profissional entrar para uma empresa em que posso fazer carreira e lá ficar a vida toda. & 3,86 & 4,00 & 1,64 \\
\hline $\begin{array}{l}\text { V12. De nada adianta eu investir na minha formação e educação já que tudo depende do mercado e dos governantes } \\
\text { para que eu tenha um emprego no futuro. }\end{array}$ & 1,96 & 1,00 & 1,46 \\
\hline $\begin{array}{l}\text { V13. Visualizo para meu futuro profissional uma carreira empreendedora, em que serei dono de minha própria } \\
\text { empresa. }\end{array}$ & 4,24 & 4,00 & 1,71 \\
\hline V14. Acredito que para eu ter sucesso profissional devo ser fiel à uma empresa e por ela me sacrificar. & 3,15 & 3,00 & 1,72 \\
\hline V15. Pretendo como profissional realizar meus sonhos, mesmo que trabalhe em várias empresas durante minha vida. & 4,51 & 5,00 & 1,54 \\
\hline V16. Acredito que sucesso profissional é ser feliz no trabalho, com a família e ter paz interior. & 5,32 & 6,00 & 1,20 \\
\hline V17. Penso em ser um funcionário público para que eu possa ajudar no desenvolvimento da sociedade em que vivo & 2,59 & 2,00 & 1,59 \\
\hline V18. Na escola sou estimulado a descobrir meu talento & 4,10 & 4,00 & 1,57 \\
\hline V19. Quero arrumar um emprego para que eu possa sobreviver e pagar minhas contas, não quero ficar rico. & 3,03 & 3,00 & 1,62 \\
\hline V20. Tenho estímulos na minha casa para que eu possa estudar e assim conseguir um futuro melhor. & 5,46 & 6,00 & 1,21 \\
\hline V21. Penso em ser um funcionário público para obter estabilidade e trabalhar pouco & 1,80 & 1,00 & 1,25 \\
\hline V22. Espero construir meu futuro profissional em São José dos Campos & 3,73 & 4,00 & 1,83 \\
\hline V23. Não vejo meu futuro profissional em São José dos Campos por que aqui é um lugar de poucas oportunidades & 2,34 & 2,00 & 1,48 \\
\hline V24. Tenho um grande sonho de vida e acredito que serei capaz de realizá-lo. & 5,42 & 6,00 & 1,07 \\
\hline V25. Não acredito em sonhos, pois o mundo real é injusto com os mais pobres. & 1,59 & 1,00 & 1,00 \\
\hline V26. A realização dos meus sonhos depende do meu esforço. & 5,88 & 6,00 & 0,52 \\
\hline V27. Não sei se conseguirei realizar meu sonho, pois ele está muito além da minha realidade de vida. & 2,29 & 2,00 & 1,58 \\
\hline $\begin{array}{l}\text { V28. O meu sonho é individual e por isso o que importa sou "eu". Não me importo com a sociedade, o importante é } \\
\text { que eu realize meu sonho. }\end{array}$ & 2,36 & 2,00 & 1,73 \\
\hline V29. Eu me julgo capaz de realizar meu sonho. & 5,20 & 6,00 & 1,26 \\
\hline V29. Eu me julgo capaz de realizar meu sonho. & 5,64 & 6,00 & 0,73 \\
\hline V30. Estou disposto ao trabalho para realizar meu sonho. & 5,45 & 6,00 & 0,96 \\
\hline V31. Eu procuro conhecer o caminho que me levará ao meu sonho & 4,42 & 5,00 & 1,51 \\
\hline V32. Uma das chaves para realização do meu sonho está nos relacionamentos que eu conquistar durante a vida & 1,44 & 1,00 & 1,16 \\
\hline V33. Em casa não tenho o apoio de meus familiares para sonhar e realizar meu sonho. & 4,88 & 5,00 & 1,30 \\
\hline V34. Reconheço que a educação que tenho na escola irá me ajudar na realização do meu sonho. & 4,45 & 5,00 & 1,50 \\
\hline V35. Tenho na escola estímulo para sonhar e realizar esse sonho. & 5,42 & 6,00 & 1,07 \\
\hline
\end{tabular}

FONTE: Os autores (2016).

LEGENDA: Escala das respostas: 1 - discordo totalmente até 6 - concordo totalmente.

FIGUEIREDO, A. C.; DEL MAESTRO FILHO, A.; SANTOS, L. M. Carreira tradicional ou moderna? Um estudo com alunos da rede municipal de ensino de São José dos Campos/SP. Revista de Empreendedorismo e Gestão de Pequenas Empresas, v.5, n.1, 2016. 
$\mathrm{Na}$ Tabela 3, verifica-se que a maior média foi observada para a variável "V26. A realização dos meus sonhos depende do meu esforço", da ordem de 5,88. Tal variável apresentou também uma mediana (50\%) de 6,00, indicando que pelo menos $50 \%$ dos entrevistados atribuíram nota máxima a essa variável. Ela foi também a que apresentou o menor desvio padrão (Desvio), de 0,52.

Já a variável que obteve a menor média foi a "V33. Em casa não tenho o apoio de meus familiares para sonhar e realizar meu sonho", de 1,44, acompanhada também por uma mediana de 1,00, indicando que pelo menos $50 \%$ dos entrevistados atribuíram nota mínima a esta variável. A variável que apresentou o maior desvio padrão foi a "V22. Espero construir meu futuro profissional em São José dos Campos", indicando maior variabilidade às respostas dadas a esta variável.

No geral, observou-se um maior grau de concordância para variáveis relacionadas ao modelo de carreira moderna e de acordo com o modelo de educação empreendedora empregado no município. Afirmativas que abordam a escolha de uma carreira dinâmica, o empoderamento na escolha da carreira e valores pessoais obtiveram maior pontuação entre as questões propostas no questionário.

A partir das respostas dos entrevistados, elaborou-se um modelo teóricohipotético (Figura 1) formado de 3 (três) construtos de segunda ordem, compostos por variáveis disponíveis nos questionários distribuídos: educação empreendedora, carreira tradicional e carreira moderna/proteana:

FIGUEIREDO, A. C.; DEL MAESTRO FILHO, A.; SANTOS, L. M. Carreira tradicional ou moderna? Um estudo com alunos da rede municipal de ensino de São José dos Campos/SP. Revista de Empreendedorismo e Gestão de Pequenas Empresas, v.5, n.1, 2016. 
FIGURA 1 - MODELO HIPOTÉTICO PROPOSTO PARA A PESQUISA.

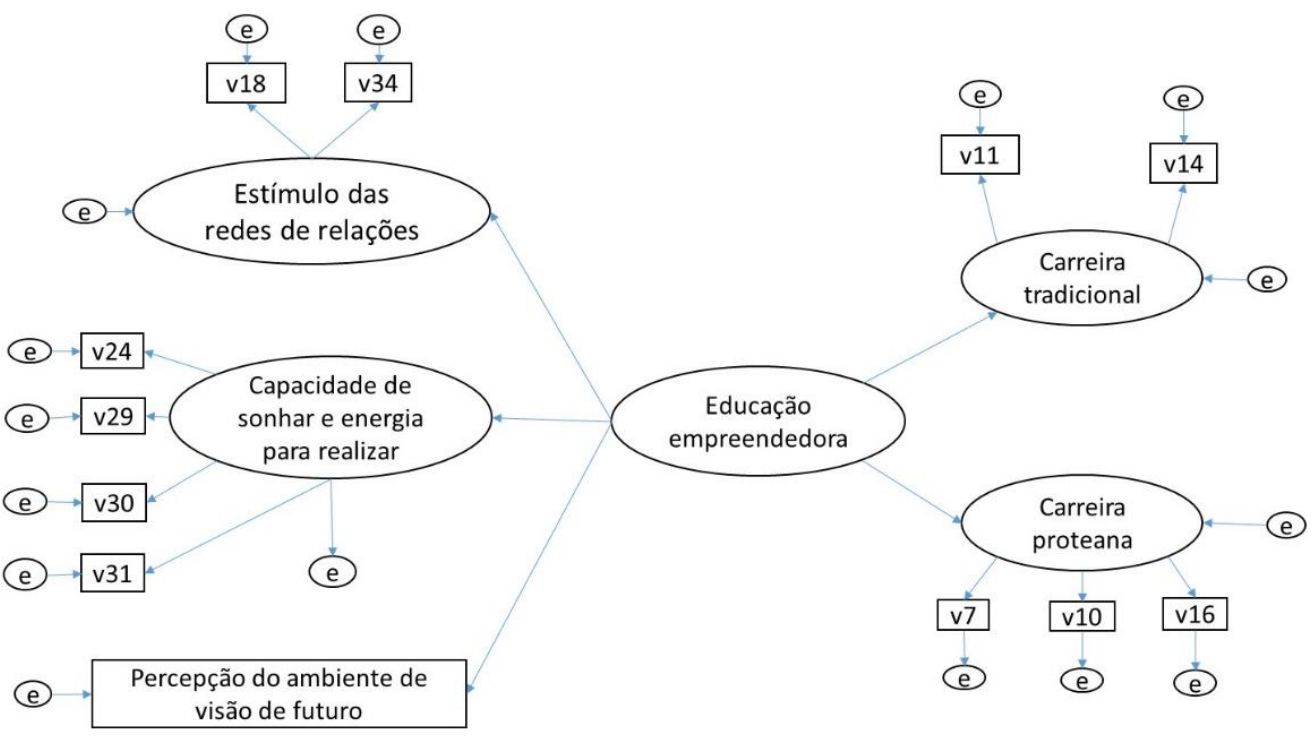

FONTE: Os autores (2016).

O construto "Educação empreendedora" foi elaborado com base na Teoria Visionária de Filion $(1993,2004)$ e no modelo de educação empreendedora defendida por Dolabela $(1999,2003)$. Nesse construto, 2 (duas) variáveis latentes e um indicador foram utilizados para compor a análise teórica do modelo, são eles: "capacidade de sonhar e energia para realizar", "estímulos das redes de relações" e "percepção do ambiente da visão de futuro".

As variáveis consideradas para a variável latente "capacidade de sonhar e energia para realizar" abrangem aspectos relacionados com a capacidade em sonhar (V24), o reconhecimento da potencialidade de realizar os sonhos (V29 e V30) e consciência sobre a importância de se conhecer o caminho para realização do sonho (V31).

As variáveis relativas ao indicador "estímulo das redes de relações" contemplam aspectos relacionados ao reconhecimento das redes de relações construídas no ambiente escolar como propulsoras importantes ao direcionamento dos indivíduos para realização de seus sonhos (V18 e V34).

FIGUEIREDO, A. C.; DEL MAESTRO FILHO, A.; SANTOS, L. M. Carreira tradicional ou moderna? Um estudo com alunos da rede municipal de ensino de São José dos Campos/SP. Revista de Empreendedorismo e Gestão de Pequenas Empresas, v.5, n.1, 2016. 
TABELA 4 - SOLUÇÃO FATORIAL DO CONSTRUTO TIPO DE CARREIRA

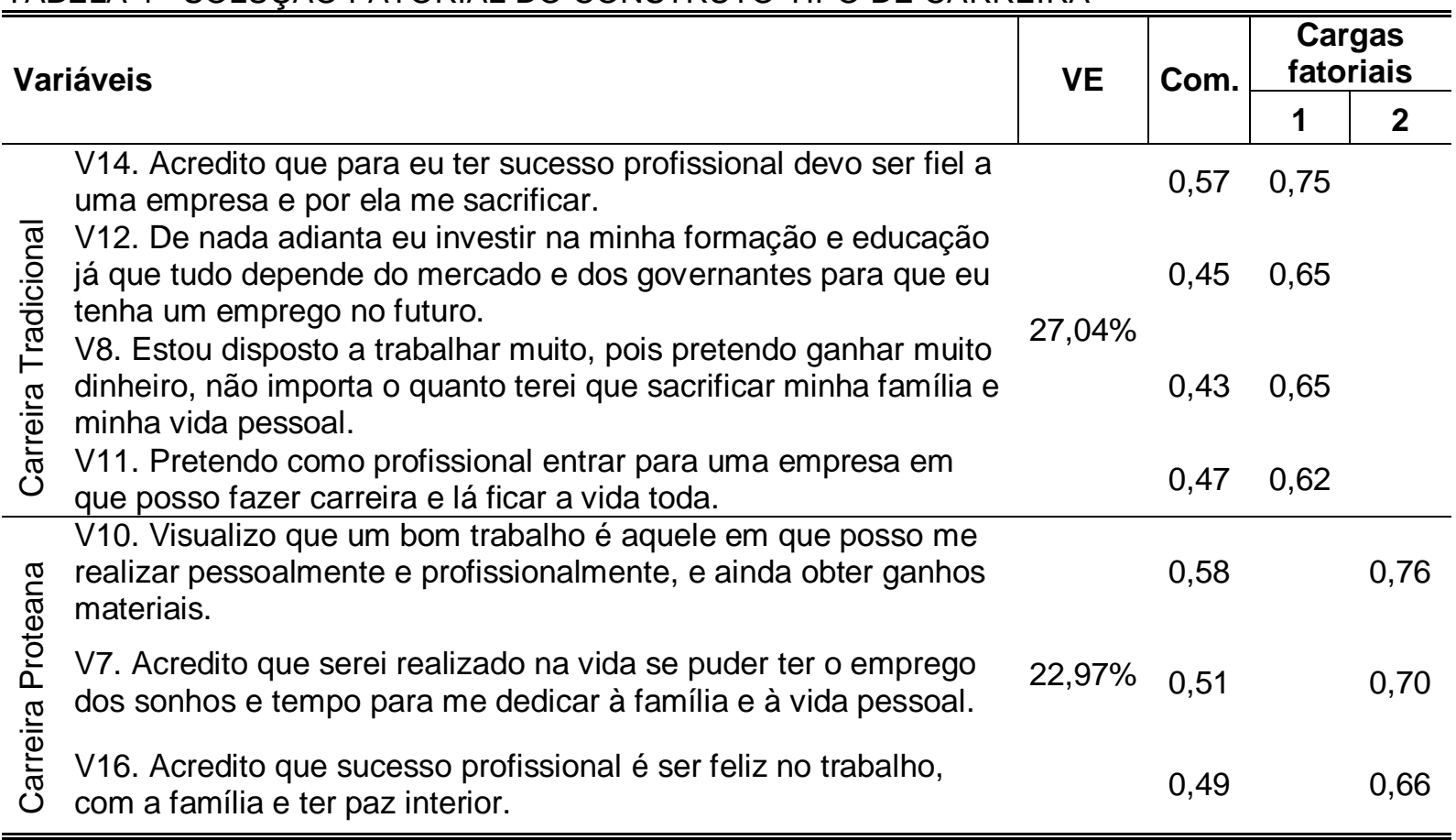

FONTE: Os autores (2016).

LEGENDA: VE - variância explicada do fator; COM. - comunalidade da variável.

Para seleção das variáveis relativas ao construto carreira tradicional e carreira proteana, foram consideradas as proposições teóricas de Chanlat (1995, 1996) e Hall (1996). O primeiro teve como indicador proposto de explicação, a visão de carreira estável em uma organização (V11 e V14). O segundo teve como indicador, a visão de carreira instável em várias empresas (V7, V10 e V16).

A análise da dimensionalidade dos construtos foi feita por meio da análise fatorial exploratória. Para o construto Tipo de Carreira, foi encontrado um KMO de 0,627, esfericidade de Barlett significativa à $1 \%$ e a variância explicada de $50,01 \%$. Tal solução apresentada na Tabela 4 apresentou consistência teórica com dois fatores, denominados: Carreira Tradicional e Carreira Proteana.

O mesmo procedimento foi realizado para o construto Educação Empreendedora e apresentado na Tabela 5. O primeiro fator encontrado foi denominado de F1 (Estímulo das redes de relações), o segundo fator de F2 (Capacidade de sonhar e energia para realizar) e o terceiro fator de F3 (Percepção do ambiente de visão do futuro).

FIGUEIREDO, A. C.; DEL MAESTRO FILHO, A.; SANTOS, L. M. Carreira tradicional ou moderna? Um estudo com alunos da rede municipal de ensino de São José dos Campos/SP. Revista de Empreendedorismo e Gestão de Pequenas Empresas, v.5, n.1, 2016. 
Utilizou-se o método de estimação por mínimos quadrados parciais (PLS) para testar os modelos de mensuração e estrutural, por meio do software SmartPLS (AMATO; ESPOSITO VINZI; TENENHAUS, 2004; RINGLE; WENDEL; WILL, 2005). Isso porque os dados da pesquisa não se comportam como uma distribuição normal e possuem apenas 185 observações (CHIN, 1998).

\section{TABELA 5 - SOLUÇÃO FATORIAL DO CONSTRUTO EDUCAÇÃO EMPREENDEDORA}

\begin{tabular}{|c|c|c|c|c|c|c|}
\hline & \multirow{2}{*}{ Variáveis } & \multirow{2}{*}{ VE } & \multirow{2}{*}{ Com. } & \multicolumn{3}{|c|}{ Fatores } \\
\hline & & & & 1 & 2 & 3 \\
\hline \multirow{3}{*}{$\mathrm{F} 1$} & $\begin{array}{l}\text { V35. Tenho na escola estímulo para sonhar e realizar esse } \\
\text { sonho. }\end{array}$ & \multirow{3}{*}{$25,52 \%$} & 0,81 & 0,90 & & \\
\hline & \multirow{2}{*}{$\begin{array}{l}\text { V18. Na escola sou estimulado a descobrir meu talento } \\
\text { V34. Reconheço que a educação que tenho na escola irá me } \\
\text { ajudar na realização do meu sonho. }\end{array}$} & & 0,73 & 0,86 & & \\
\hline & & & 0,55 & 0,60 & & \\
\hline \multirow{4}{*}{ F2 } & $\begin{array}{l}\text { V24. Tenho um grande sonho de vida e acredito que serei } \\
\text { capaz de realizá-lo. }\end{array}$ & \multirow{4}{*}{$21,70 \%$} & 0,50 & & 0,70 & \\
\hline & V29. Eu me julgo capaz de realizar meu sonho. & & 0,52 & & 0,69 & \\
\hline & $\begin{array}{l}\text { V31. Eu procuro conhecer o caminho que me levará ao meu } \\
\text { sonho }\end{array}$ & & 0,46 & & 0,66 & \\
\hline & V30. Estou disposto ao trabalho para realizar meu sonho. & & 0,43 & & 0,65 & \\
\hline \multirow{2}{*}{ F3 } & $\begin{array}{l}\text { V22. Espero construir meu futuro profissional em São José } \\
\text { dos Campos }\end{array}$ & \multirow[b]{2}{*}{$13,67 \%$} & 0,75 & & & 0,86 \\
\hline & $\begin{array}{l}\text { V23. Não vejo meu futuro profissional em São José dos } \\
\text { Campos por que aqui é um lugar de poucas oportunidades }\end{array}$ & & 0,73 & & & $0, \overline{8}$ \\
\hline
\end{tabular}

FONTE: Os autores (2016).

LEGENDA: VE - variância explicada do fator; COM. - comunalidade da variável.

Os construtos de primeira ordem foram então transformados em variáveis de segunda ordem, de acordo com o modelo de dois passos propostos por Wilson e Henseler (2007), que consiste em analisar um modelo somente com os construtos de primeira ordem e verificar o modelo de mensuração. Estando adequada, é feita uma transformação dos construtos de primeira ordem em variáveis, utilizando a seguinte fórmula:

$$
\text { Construto de segunda ordem (variável) }=\frac{\sum_{i=1}^{x} L \times E}{\sum_{i=1}^{x} L} \quad \text { (Equação 1) }
$$

$\mathrm{L}=$ Carga estrutural padronizada da variável no construto

$E$ = Nota de concordância / discordância atribuída pelo entrevistado

$X=$ Número de variáveis que irão compor o índice.

FIGUEIREDO, A. C.; DEL MAESTRO FILHO, A.; SANTOS, L. M. Carreira tradicional ou moderna? Um estudo com alunos da rede municipal de ensino de São José dos

Campos/SP. Revista de Empreendedorismo e Gestão de Pequenas Empresas, v.5, n.1, 2016. 
Assim, após o cálculo mencionado anteriormente, o modelo é processado novamente, sendo necessário garantir que os construtos de segunda ordem apresentem um modelo de mensuração adequado para então verificar a validade nomológica e o ajuste do modelo estrutural.

Foi observado uma validade convergente tanto para os construtos de primeira ordem, quanto para os de segunda ordem, segundo os critérios de Bagozzi, Yi e Philips (1991), com significância das cargas inferiores a 1\%. Entretanto, as varáveis V23_INV, V8, V35 e V12 não apresentaram validade convergente com os seus respectivos construtos e tiveram de ser eliminadas da análise.

Da mesma forma, foram obtidos valores de AVE para os construtos de primeira e segunda ordem, de acordo com o critério de Fornell e Lacker (1981), e pôde-se atestar também a validade convergente destes. Como o construto F3 (Percepção do ambiente de visão do futuro) passou a ser mensurado por apenas uma variável, não pôde mais ser tratado como construto e, portanto, não apresentará valor de AVE nem de confiabilidade.

Por fim, foi avaliada a confiabilidade dos construtos por meio da confiabilidade convergente. Os resultados obtidos mostraram que todos os construtos de primeira e segunda ordem apresentaram confiabilidade convergente acima dos limites aceitáveis, de $60 \%$. Tais resultados apresentados garantem que 0 Outer Model é adequado, podendo então ser avaliado o Inner Path Model de modo a testar as hipóteses da pesquisa (MACKENZIE, 2001; RINGLE; WENDES; WILL, 2005; WILSON; HENSELER, 2007).

A Figura 2 exibe o teste do Modelo Proposto pela Figura 1. Verifica-se que o construto Educação Empreendedora é capaz de explicar 3\% das variações do construto Carreira Tradicional e $12 \%$ das variações do construto Carreira Moderna/Proteana. O primeiro apresenta uma carga positiva e estatisticamente significativa de 0,16 e o segundo, uma carga positiva e estatisticamente significativa de 0,34

Ainda que ambas sejam positivas e estatisticamente significativas, verificase que os estudantes deram maior peso para variáveis no questionário que representam aspectos da Carreira Moderna/Proteana. No entanto, os estudantes

FIGUEIREDO, A. C.; DEL MAESTRO FILHO, A.; SANTOS, L. M. Carreira tradicional ou moderna? Um estudo com alunos da rede municipal de ensino de São José dos Campos/SP. Revista de Empreendedorismo e Gestão de Pequenas Empresas, v.5, n.1, 2016. 
ainda percebem aspectos da carreira Tradicional como importantes, dado que foi possível identificar uma relação positiva e significativa.

FIGURA 2 - MODELO PROPOSTO NA PESQUISA.

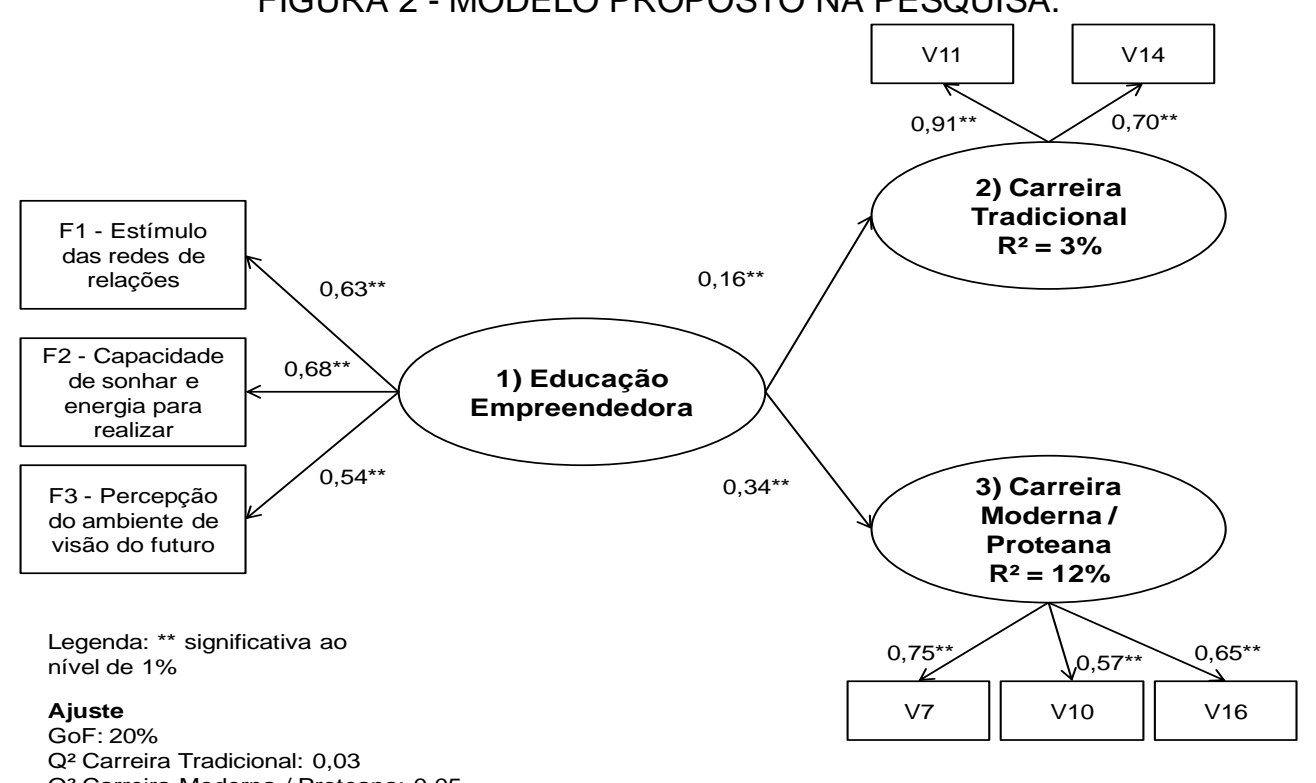

$\mathrm{Q}^{2}$ Carreira Moderna / Proteana: 0,05

FONTE: Os autores (2016).

Observa-se que o $Q^{2}$ dos construtos endógenos do modelo indicaram um poder adequado de previsão do modelo. Já o GoF foi de $20 \%$. Apesar do valor não ser elevado, deve-se considerar que as hipóteses do modelo não eram de prever os dois construtos endógenos, mas somente um. Dessa forma, um $\mathrm{R}^{2}$ baixo para 0 construto Carreira Tradicional era desejado e foi encontrado, o que provocou a redução do valor do GoF. Dessa forma, pode-se considerar que o modelo testado possui um ajuste adequado (MACKENZIE, 2001; RINGLE; WENDE; WILL, 2005; WILSON; HENSELER, 2007; HAIR; RINGLE; SARSTEDT, 2011; HAIR et al., 2012).

A característica exploratória do estudo levou o foco para o desenvolvimento do modelo proposto e a avaliação das dimensões de educação empreendedora, bem como a carreira proposta pela literatura e o modelo empregado no município estudado. Dessa forma, pode-se concluir a apresentação dos resultados levantados na presente pesquisa e passar ao capítulo seguinte que irá abordar as conclusões, limitações do estudo e recomendações para melhoria em futuras pesquisas sobre o tema.

FIGUEIREDO, A. C.; DEL MAESTRO FILHO, A.; SANTOS, L. M. Carreira tradicional ou moderna? Um estudo com alunos da rede municipal de ensino de São José dos

Campos/SP. Revista de Empreendedorismo e Gestão de Pequenas Empresas, v.5, n.1, 2016. 


\section{Considerações Finais}

Dentro da validade comprovada do modelo, pode-se inferir a comprovação dos pressupostos teóricos que dão base a essa pesquisa, assim como também se ratifica o alcance do objetivo principal sugerido para a realização deste trabalho. Em outras palavras, pode-se verificar entre os entrevistados, a existência de uma consciência sobre a responsabilidade pessoal na construção de sua carreira profissional.

Outro ponto relevante observado está na consciência da amostra pesquisada com relação ao sonho de vida e a capacidade de realizá-lo. Os estudantes apresentaram maior concordância com as variáveis apresentadas que abordam que a realização de seus sonhos depende de seus esforços e com isso tendem a adotar uma postura mais ativa em suas vidas, sem esperar que os outros façam por eles.

Esse achado pode ser decorrente da eficácia da implementação do modelo de educação do município de São José dos Campos para o empoderamento dos jovens no desenho de sua própria carreira. Por outro lado, apesar da visão dos estudantes estar voltada para o empoderamento pessoal na busca de seus sonhos, não há evidências de que exista substituição de uma visão por outra. Aspectos da carreira tradicional ainda se mostram relevantes na percepção da amostra analisada neste estudo, apesar das evidências apresentarem maior tendência para a carreira Moderna/Proteana.

Com relação ao conceito de sucesso profissional visualizado pela amostra investigada, percebe-se que os jovens inseridos na pesquisa já têm percepção sobre o mercado de trabalho, suas capacidades e autonomias para construírem suas carreiras. É possível, dessa forma, verificar que esses estudantes já se predispõem a um comportamento cujo perfil demonstra uma tendência a buscar uma carreira profissional futura do tipo Moderna/Proteana.

A realização dessa pesquisa possibilitou aos pesquisadores, apresentar e avaliar parcialmente um sistema de ensino público que se destaca no Brasil pela estrutura física e políticas de educação. O programa de educação empreendedora

FIGUEIREDO, A. C.; DEL MAESTRO FILHO, A.; SANTOS, L. M. Carreira tradicional ou moderna? Um estudo com alunos da rede municipal de ensino de São José dos Campos/SP. Revista de Empreendedorismo e Gestão de Pequenas Empresas, v.5, n.1, 2016. 
desenvolvido no município de São José dos Campos há 12 anos é reconhecido como um dos diferenciais na formação de indivíduos mais preparados para a vida profissional. As escolas municipais de São José dos Campos se destacam pela estrutura, organização do espaço físico e trata-se de um exemplo no qual se destaca a importância das políticas públicas na geração de uma sociedade mais ativa e capaz de proporcionar condições para todos os cidadãos que queiram sonhar e realizar seus sonhos.

Assim, conclui-se que os propósitos apresentados pela educação empreendedora, no que se refere a desenvolver competências e habilidades relacionadas ao protagonismo de vida e uma visão de carreira futura mais voltada para o tipo moderna/proteana, são confirmados na análise desta pesquisa. Isso vem ratificar a relação positiva e estatisticamente positiva entre educação empreendedora e visão de carreira moderna/proteana. Contudo, influências de outros aparelhos sociais ainda mantêm a percepção sobre a importância de aspectos da Carreira Tradicional.

No que se diz respeito a limitações do estudo, destaca-se a ausência de instrumentos de pesquisa já validados anteriormente que pudessem oferecer exatidão e confiança na aplicação da pesquisa. O questionário utilizado ainda precisa de ajustes a fim de garantir melhor agrupamento de variáveis para testar o modelo estrutural proposto. Os dados foram coletados em uma única cidade que, apesar de ser modelo para o Brasil em educação empreendedora, não garante a generalização dos resultados desse tipo de metodologia de ensino.

Vale mencionar ainda que o método quantitativo utilizado no estudo não é por si só suficiente para explicar os fenômenos em ciências sociais, pois mesmo que use instrumentos estatísticos sofisticados para análise dos dados, pode incorrer no desconhecimento de aspectos importantes dos fenômenos e processos sociais estudados (MINAYO; SANCHES, 1993).

A literatura sobre educação empreendedora ainda é pouco explorada no Brasil. Isso dificultou o acesso a resultados de outras pesquisas nas quais sustentariam de forma mais abrangente o referencial teórico deste trabalho. Para minimizar as limitações apresentadas, sugere-se que seja feita uma colimação do

FIGUEIREDO, A. C.; DEL MAESTRO FILHO, A.; SANTOS, L. M. Carreira tradicional ou moderna? Um estudo com alunos da rede municipal de ensino de São José dos Campos/SP. Revista de Empreendedorismo e Gestão de Pequenas Empresas, v.5, n.1, 2016. 
instrumento de pesquisa a fim de melhorar as relações de análise entre as variáveis propostas.

Com a finalidade ampliar os estudos e aumentar o grau de confiabilidade e generalização dos resultados, sugere-se aplicar a pesquisa em outros municípios brasileiros. Assim, aumentaria a amostra estudada e garantiria maior abrangência ao estudo. Outra recomendação que daria maior suporte à confirmação dos resultados da educação empreendedora é o desenvolvimento de pesquisas comparativas, isto é, promover a mesma pesquisa em outros municípios que não existe nenhum tipo de programa para o desenvolvimento do empreendedorismo e observar as percepções sobre as preferências pelos tipos de carreiras. Comparando os resultados, será possível confirmar ou não o diferencial que a educação empreendedora proporciona aos indivíduos de uma sociedade na preferência por determinado tipo de carreira.

Por fim, vale dizer um último ponto a se recomendar em uma pesquisa futura. Este, consiste em, aliado ao método quantitativo, complementar a pesquisa com análises qualitativas como, por exemplo, por meio de entrevistas e grupos focais com indivíduos que estejam dentro dos padrões da amostra estudada. Isso garantiria a complementaridade das informações com abordagem de aspectos sociais não abordados no instrumento de pesquisa quantitativa.

\section{Referências:}

ACKAH, C.; HEATON, N. The reality of "new" careers for men and for women. Journal of European Industrial Training, v. 28, n. 2, p. 141-158, 2004.

AMATO, S.; ESPOSITO VINZI, V.; TENENHAUS, M. A global goodness-of-fit index for PLS structural equation modeling. In: Proceedings of the XLII SIS scientific meeting. 2004.

ANDRADE, G. A.; KILIMNIK, Z.M.; PARDINI, D.J. Carreira Tradicional versus Carreira Autodirigida ou Proteana: um estudo comparativo sobre a satisfação com a carreira, a profissão e o trabalho. Revista de Ciências da Administração, v. 12, n. 31, p. 58-80, set./dez. 2011.

BAGOZZI, R. P.; YI, Y.; PHILIPS, L. W. Assessing construct validity in organizational research. Administrative Science Quartely, v. 36, n. 3, p. 421-458, set. 1991.

BALASSIANO, M.; VENTURA, E. C. F.; FONTES FILHO. J. R. Carreiras e Cidades: Existiria um Melhor Lugar para se Fazer Carreira? Revista de Administração

Contemporânea, v. 8, n. 3, p. 99-116, jul./set. 2004.

FIGUEIREDO, A. C.; DEL MAESTRO FILHO, A.; SANTOS, L. M. Carreira tradicional ou moderna? Um estudo com alunos da rede municipal de ensino de São José dos Campos/SP. Revista de Empreendedorismo e Gestão de Pequenas Empresas, v.5, n.1, 2016. 
BARNETT, V. Sample survey: principles and methods. London: Arnold, 1991.

BARUCH, Y. Transformações nas Carreiras: de trajetórias lineares para multidirecionais: perspectivas organizacionais e individuais. In: KILIMNIK, Z. M. (organizadora). Transformações e transições nas carreiras: estudos nacionais e internacionais sobre o tema. Rio de Janeiro: Qualitymark, 2011.

BENDASSOLLI, P.F. Recomposição da relação sujeito-trabalho nos modelos emergentes de carreira. Revista de Administração de Empresa, v. 49, n. 4, p. 387400, out./dez. 2009.

BRASIL. Presidência da República. Casa Civil. Subchefia de Assuntos Jurídicos. Lei 9.394, de 20 de dezembro de 1996. Estabelece as diretrizes e bases da educação Nacional. Brasília: Senado Federal, $2005 . \quad$ Disponível em: http://www2.senado.leg.br/bdsf/bitstream/handle/id/70320/65.pdf?sequence=3. Acesso em: 31 maio 2016.

CHANLAT, J. F. Quais carreiras e para qual sociedade? (I). RAE - Revista de Administração de Empresas, v. 35, n. 6, p. 67- 75, 1995.

. Quais carreiras e para qual sociedade? (II). RAE - Revista de Administração de Empresas, v. 36, n. 1, p. 13-20, 1996.

CHIN, W. W. Issues and Opinion on Structural Equation Modeling. MIS Quarterly, v. 22, n.1, 1998.

DOLABELA, F. Oficina do empreendedor: a metodologia de ensino que ajuda transformar conhecimento em riqueza. São Paulo: Cultura Editores Associados, 1999.

Pedagogia empreendedora. São Paulo: Editora de Cultura, 2003,

EVANS, P. Carreira, sucesso e qualidade de vida. RAE - Revista de Administração de Empresas, v. 36, n. 3, p. 14-22, 1996.

EASTERBY-SMITH, M.; THORPE, R.; LOWE, A. Management Research: An Introduction. London: Sage Publications, 1991.

FERNANCEZ, V.; ENACHE, M. Exploring the relationship between protean and boundaryless career attitudes and affective commitment through the lens of a fuzzy set QCA methodology. Intangible Capital, v. 4, n. 1, p. 31-66, 2008.

FILION, L. J. Visão e relações: elementos para um metamodelo empreendedor. RAE Revisitada, v. 33, n. 6, p. 50-61, 1993.

Um roteiro para desenvolver o empreendedorismo. Recife: IEL,

FIGUEIREDO, A. C.; DEL MAESTRO FILHO, A.; SANTOS, L. M. Carreira tradicional ou moderna? Um estudo com alunos da rede municipal de ensino de São José dos Campos/SP. Revista de Empreendedorismo e Gestão de Pequenas Empresas, v.5, n.1, 2016. 
2004.

FILION, L. F.; LAFERTÉ, S. Carte routière pour um Québec entrepreneurial. Montreal: HEC, 2003.

FORNELL, C.; LARCKER, D. F. Evaluating structural equation models with unobservable variables and measurement error. Journal of Marketing Research, v. 18, p. 39-50, fev. 1981.

FORNELL, C.; BOOKSTEIN, F. L. Two structural equation models: LISREL and PLS applied to consumer exit-voice theory. Journal of Marketing Research, v. 19, p. 440-452, 1982.

GIL, A. C. Como elaborar projetos de pesquisa. 5. ed. São Paulo: Atlas, 2010.

HAENLEIN, M.; KAPLAN, A. M. A beginner's guide to partial least squares (PLS) analysis. Understanding statistics, v. 3 n. 4, p. 283-297, 2004.

HAIR, J. F. et al. Análise Multivariada de Dados. Trad: Adonai Schlup Sant'Anna. Porto Alegre: Bookmam, 2009.

HAIR, J. F.; RINGLE, C. M.; SARSTEDT, M. PLS-SEM: Indeed a Silver Bullet. Journal of Marketing Theory and Practice, v. 19, n. 2, p. 139-151, 2011.

HAIR, J. F.; SARSTEDT, M.; RINGLE, C. M.; MENA, J. A. An assessment of the use of partial least squares structural equation modeling in marketing research. Journal of the Academy of Marketing Science, v. 40, n. 3, p. 414-433, 2012.

HALL, D. T. Protean careers of the 21st century. Academy of Management Executive, v. 10, n. 4, p. 8-16, nov. 1996.

HENSELER, J.; RINGLE, C. M.; SINKOVICS, R. R. The Use of Partial Least Squares Path Modeling in International Marketing. Advances in International Marketing, $v$. 20, n. 1, p. 277-319, 2009.

INSTITUTO BRASILEIRO DE GEOGRAFIA E ESTATÍSTICA - IBGE. Cidades@. Disponível

http://www.cidades.ibge.gov.br/xtras/perfil.php?lang=\&codmun=354990\&search=sao -paulo|sao-jose-dos-campos. Acesso em: 31 maio 2016.

LEMOS, A. H. C. Empregabilidade e individualização na conquista do emprego. In: BALASSIANO, M.; COSTA, I. S. A. (organizadores). Gestão de carreiras: dilemas e perspectivas. São Paulo: Atlas, 2010.

LOPES, R. M. A.; TEIXEIRA, M. A. A. Educação empreendedora no ensino fundamental: o caso da educação municipal de São José dos Campos. In: LOPES, R. M. A. Educação empreendedora: conceitos, modelos e práticas. Rio de Janeiro:

FIGUEIREDO, A. C.; DEL MAESTRO FILHO, A.; SANTOS, L. M. Carreira tradicional ou moderna? Um estudo com alunos da rede municipal de ensino de São José dos Campos/SP. Revista de Empreendedorismo e Gestão de Pequenas Empresas, v.5, n.1, 2016. 
Elsevier; São Paulo: Sebrae, 2010.

MACKENZIE, S. B. Opportunities for Improving Consumer research Through latent Variable Structural Equation Modeling. Journal of Marketing Research, v. 28, n. 1, p.159-166, 2001.

MAROCO, J. Análise Estatística: com utilização do SPSS. 3. ed. Lisboa: Edições Sílabos, 2007.

MINARELLI, J.A. Empregabilidade, como entrar, permanecer e progredir no mercado de trabalho. 25ํㅡㄹ edição. São Paulo: Editora Gente 2010.

MINAYO, M. C. S.; SANCHES, O. Quantitativo-Qualitativo: Oposição ou Complementaridade? Cadernos de Saúde Pública, v. 9, n. 3, p. 239-262, jul./set. 1993.

PAIVA, V. Educação e mundo do trabalho. Notas sobre formas alternativas de inserção de setores qualificados. Contemporaneidade e Educação, n. 4, p. 8-21, 1998.

RINGLE, C. M.; WENDE, S.; WILL, A. 'SmartPLS 2.0. 2005. Disponível em: $<$ www.smartpls.de>. Acesso em: 15 ago. 2011.

TABACHNICK, B. G.; FIDELL, L. S. Using Multivariate Statistics. 3 ed. New York: HarperCollins, 2001.

VERGARA, S. C. Projetos e relatórios de pesquisa em administração. 12. ed. São Paulo: Atlas, 2010.

WILSON, B.; HENSELER, J. (2007). Modeling reflective higher-order constructs using three approaches with PLS path modeling: a Monte Carlo comparison.

Australian and New Zealand Marketing Academy Conference, Otago, Australia, December 3-5.

FIGUEIREDO, A. C.; DEL MAESTRO FILHO, A.; SANTOS, L. M. Carreira tradicional ou moderna? Um estudo com alunos da rede municipal de ensino de São José dos Campos/SP. Revista de Empreendedorismo e Gestão de Pequenas Empresas, v.5, n.1, 2016. 